\title{
LOS FRANCISCANOS EN CUBA: DE LA RESTAURACIÓN A LA REVOLUCIÓN (1887-1961)
}

\author{
POR \\ JuAn Bosco Amores CARredano \\ Universidad del País Vasco
}

\begin{abstract}
RESUMEN
La desamortización y exclaustración acabó con la presencia de la mayoría de las ordenes religiosas en Cuba a mediados del siglo XIX, e inició un proceso creciente de secularización en la sociedad cubana, en cuyas clases media y alta era ya visible un claro indiferentismo religioso. Aunque tras la firma del concordato entre España y la Santa Sede en 1851, las órdenes religiosas fueron autorizadas a regresar a la isla, los franciscanos no lo hicieron hasta 1887, experimentando un crecimiento constante de su presencia y actividad pastoral desde la independencia de la isla hasta el triunfo de la revolución castrista en 1959. Adaptándose perfectamente a las necesidades de la sociedad cubana de la época, la labor de los franciscanos destacó en los campos de la educación elemental, la asistencia social y la dirección espiritual del asociacionismo laico católico, en especial la Acción Católica.
\end{abstract}

PALABRAS ClaVE: Historia de la Iglesia, Cuba, siglos XIX-XX, orden franciscana.

\section{ABSTRACT}

The disentailment and secularization finished with the presence of the majority of the religious orders in Cuba in the middle of the XIXth century, and initiated an increasing process of secularization the Cuban society, whose upper and middle classes it happens and high already visible age a clear religious «indiferentismo". Though after the signature of the concordat between Spain and the Holy See in 1851, the religious orders were authorized to return to the island, the Franciscans did not do it until 1887, experiencing since then a constant growth of his presence and pastoral activity from the independence of the island up to the victory of the revolution castrista in 1959. Adapting perfectly to the 
needs of the Cuban society of the epoch, the labor of the Franciscans emphasized in the fields of the elementary education, the social assistance and the spiritual direction of the lay catholic asociations, especially the «Acción católica".

KEY WORDS: History of de Catholic Church, Cuba, XIX-XXth centuries, Franciscans.

\section{LA IgLeSIA en AmÉRICA LATINA EN LA SEGUNDA MITAD DEL SIGLO XIX}

La Iglesia sufrió en América latina, a mediados del siglo XIX, el mismo ataque frontal por parte del liberalismo revolucionario que en el resto del mundo católico de occidente. En algunos países de esta región, el ataque fue incluso más virulento debido a que la nueva generación liberal, romántica y revolucionaria, veía a la Iglesia como la principal responsable del atraso de las sociedades americanas y el mayor obstáculo para dar el salto a eso que llamaban el mundo moderno, la construcción de la república de ciudadanos; era, sin duda, el culpable más fácil de identificar y todavía hoy una buena parte de la historiografía no ha rectificado un discurso tan simple. Como es evidente, la gran mayoría del pueblo latinoamericano hizo caso omiso de la propaganda y de la política liberal, pero no pudo evitar que se produjera una fuerte destrucción de las estructuras eclesiales: la mayoría de las ordenes religiosas fueron expulsadas de la mayoría de los países, los seminarios diocesanos casi desaparecieron, etc. ${ }^{1}$.

Pasados los vientos liberal revolucionarios, la lenta pero decisiva restauración de la Iglesia en el subcontinente comenzó, en líneas generales, después de 1860. Los liberales se aburguesaron, instalándose gobiernos oligárquicos, de filiación masónica en la mayoría de los casos, pero que permitieron o incluso favorecieron la restauración de la Iglesia porque se encargaba de paliar, con sus escuelas e instituciones de asistencia social, las consecuencias más negativas del modelo económico, ultraliberal y capitalista, que sustentaban aquellos gobiernos: el caso de México durante el mandato de Porfirio Díaz es paradigmático en este sentido. Coincide esta etapa, el último cuarto del siglo XIX, con el pontificado de León XIII, el primer papa que aceptó abiertamente el mundo moderno y puso las bases para afrontar sus retos. De todas formas costó mucho tiempo rehacer los seminarios y que se recuperara el clero diocesano. Por ello, durante más de medio siglo, el peso de la restauración de la Iglesia recayó principalmente en la llegada masiva de miembros de las an-

${ }^{1}$ Cf. John LyNCH, «La Iglesia católica en América Latina, 1830-1930», en Leslie BetheLL (ed.), Historia de América Latina, vol. 8, América Latina: cultura y sociedad, 1830-1930, Barcelona, Crítica, 1991, pp. 65-122. Los casos más conocidos son los de México en el periodo de La Reforma (18551875), cuyo ejemplo se extendió a Guatemala y parte de Centroamérica, la época de la revolución liberal en Colombia (ca. 1850-1878), y el Ecuador anterior a García Moreno (ca. 1850-1865).

Hispania Sacra, LVIII

118, julio-diciembre 2006, 755-769, ISSN: 0018-215-X 
tiguas órdenes y de las nuevas congregaciones religiosas, sobre todo desde España $^{2}$.

Cuba no fue una excepción en esta tendencia general, más bien todo lo contrario, pero con matices importantes derivados de su condición colonial hasta 1898. La Iglesia sufrió también aquí los embates del liberalismo anticlerical, en este caso español, mediante la aplicación de las leyes desamortizadoras y de exclaustración, primero con el gobierno liberal en 1820-22 y luego, de forma más incisiva, en el bienio 1839-41. La desamortización y exclaustración acabó con la presencia de la mayoría de las ordenes religiosas en la isla e inició un proceso creciente de secularización en la sociedad cubana, al producirse una seria disminución del clero e incrementarse la desatención pastoral que ya venía sufriendo la población, especialmente la campesina (incluida, por supuesto, la esclava). La desamortización también afectó el lazo que existía entre la burguesía criolla tradicional y la Iglesia, tanto por la presencia de miembros de esa burguesía en las ordenes religiosas, en especial franciscanos y dominicos, como también de sus capitales, en forma de bienes inmuebles o de censos, además de que una parte de los que tenían acceso a estudios medios o superiores lo hacían en las escuelas de los conventos de esas ordenes ${ }^{3}$.

Se ha señalado con acierto que el expolio de la iglesia cubana por parte del gobierno español explica en buena medida el descenso de la influencia de la Iglesia en Cuba en la segunda mitad del siglo XIX ${ }^{4}$. En 1853, el que fuera capitán general José Gutiérrez de la Concha, calificaba la situación de la Iglesia en la isla de «tristísima (...) hasta el punto de poder decirse, no ya de la población esclava (...) sino de la misma gente blanca y de color, que una buena parte de ella nace, vive, se enlaza y muere sin tener quien le bautice, case y entierre $»^{5}$.

Tras la firma del concordato entre España y la Santa Sede en 1851, las órdenes religiosas fueron autorizadas a regresar a la isla, pero se dio prioridad a las viejas y nuevas ordenes y congregaciones, masculinas y femeninas, que se dedicaran a la enseñanza, y que en las décadas posteriores abrieron un buen número de colegios en las principales ciudades del país. En 1852 llegaron a la provincia de Oriente las religiosas de la Enseñanza de María Inmaculada. En

${ }^{2}$ Cf. Juan B. Amores CARREDANo, «Iglesia y Estado en América Latina durante el siglo XIX», en Ernesto GARCíA FERNÁNDEZ (coord.), El poder en Europa y América: mitos, tópicos y realidades, Vitoria, Universidad del País Vasco, 2001, pp. 235-249.

${ }^{3}$ Cf. Juan B. Amores CARREDANO, «La desamortización de los bienes de regulares en Cuba», Luis E. GonZÁlez VAles (coord.), Actas del XIII Congreso Internacional de Historia del Derecho Indiano, t. II, San Juan de Puerto Rico, 2003, pp. 91-107. Sobre la labor educativa de los conventos de las órdenes religiosas en Cuba hasta 1820, véase Teresa Fernández SoneIRA, Cuba: Historia de la educación católica 1582-1961, t. I, Miami, Ediciones Universal, 1997, pp. 29-120.

${ }^{4}$ Leví Marrero, Cuba: economía y sociedad, v. 13, Madrid, editorial Playor, 1987, p. 116.

5 José GutiérReZ de la ConCha, Memoria sobre el estado político, gobierno y administración de la Isla de Cuba, Madrid, 1853, pp. 113-115. 
febrero del año siguiente regresaron los jesuitas, que fundan el famoso colegio de Belén, en La Habana, en 1854. Los Escolapios llegaron en 1857 y se hicieron cargo de la nueva Escuela Normal para la formación de maestros - la única de la isla - de Guanabacoa, cerca de La Habana; en 1858 fundaron un Liceo en Puerto Príncipe (Camagüey), la segunda ciudad de la isla, en la región centro oriental. En 1863 llegaron los Padres Paúles, que se hicieron cargo de la importante parroquia de La Merced, en el centro de La Habana, y comenzaron enseguida sus famosas misiones populares. Por parte femenina, habían llegado las Hermanas del Sagrado Corazón, que abrirán colegios en La Habana y Sancti Spiritus. Las Hijas de la Caridad atendían todos los hospitales y se hicieron cargo de dos colegios de niñas pobres en La Habana. Por su parte, el celoso y perseguido Antonio María Claret, arzobispo de Santiago de Cuba (1851-1857), fundó un centro educativo modélico en Puerto Príncipe (Camagüey) y la Congregación de Religiosas de la Enseñanza ${ }^{6}$.

Pero esta «restauración» fue vista por una buena parte de la burguesía criolla como una parte de la política de la metrópoli en su esfuerzo por españolizar la isla y contrarrestar así el sentimiento nacionalista, que creció con fuerza a lo largo de la primera guerra de independencia (1868-1878). En esa burguesía — abogados, médicos y periodistas, intelectuales y hacendados medianos-, que gozaba de una presencia relevante en la prensa, en los foros intelectuales y en algunos centros de enseñanza de mentalidad liberal y laicista, era palpable una fuerte influencia de los Estados Unidos, en cuyas universidades se habían educado muchos de ellos ${ }^{7}$. Algunos de sus miembros más influyentes reproducían el discurso ya manejado por los libertadores americanos a principios de siglo, el de que todos los males de Cuba se debían al dominio colonial español, del que hacía parte la Iglesia, que sufrió en esas décadas el estigma de «institución españolista»y, por tanto, colonialista. Pocos de ellos se confesaban católicos, pero su anticlericalismo acababa donde empezaba su nacionalismo: así, mientras el clero español era un instrumento de opresión, el clero cubano era presentado generalmente como un ejemplo de patriotismo. Además, en el caso de Cuba, y a diferencia de la América continental, hay que constatar un ambiente general de indiferentismo religioso entre la mayoría de la población, que sin duda está muy relacio-

\footnotetext{
${ }^{6}$ Reynerio Lebroc Martínez, Cuba: Iglesia y sociedad (1830-1860), Madrid, 1976, y, del mismo, San Antonio María Claret, arzobispo misionero de Cuba, Madrid, 1992.

7 El rector de la Universidad de La Habana se quejaba al ministro de Ultramar, en plena guerra de los Diez Años, de que en muchos centros de enseñanza de la isla se ponía en manos de la juventud «libros que tratan de la historia de los Estados Unidos y de la vida y hechos de los más exaltados insurrectos y en los que se lee que "con los españoles no se debe ir ni aún al cielo", haciendo calculada omisión de las glorias de España» (Juan B. Amores CARREDANo, «La Universidad de La Habana al final del periodo colonial: un informe del Rector de 1874», en Estudios de Historia social y económica de América, n. ${ }^{\circ}$ 9, Alcalá de Henares, 1992, pp. 235-243).
} 
nado, entre otros factores, con el hecho del mantenimiento hasta 1886 del sistema esclavista ${ }^{8}$.

A medida que se acercaba el final del siglo, las diferencias entre los que estaban a favor y en contra del dominio español se acentuaban. En ese contexto, el nombramiento en 1887 de Manuel Santander y Frutos, un conocido ultramontanista, como nuevo obispo de La Habana no favoreció precisamente un cambio de la opinión pública cubana hacia la Iglesia ${ }^{9}$.

Irónicamente, fue la independencia la que dio una nueva oportunidad a la Iglesia en Cuba, precisamente en un momento en el que se estaba produciendo una fuerte recuperación de la actividad eclesial en todo el mundo, gracias a los grandes pontificados de León XIII y Pío X.

\section{LA RESTAURACIÓN DE LAS MISIONES FRANCISCANAS EN CUBA}

En América latina, la restauración de la orden franciscana comenzó pronto, en 1838, en los países donde apenas se habían padecido procesos de desamortización como Chile, Bolivia, Perú y Argentina. Hasta principios del siglo XX no se reorganizan las antiguas provincias franciscanas en el continente, ya bajo el signo de la unidad de las distintas familias como Orden de Frailes Menores ${ }^{10}$.

Hacia 1842, cuando se aplica en Cuba la ley de desamortización y exclaustración, existían ocho comunidades o conventos de franciscanos, con 90 frailes (65 sacerdotes y 25 legos), la mayoría de los cuales se exiliaron a otros países de América, aunque unos pocos permanecieron en la isla como «congregantes» entre el clero secular ${ }^{11}$.

La restauración de la orden seráfica en Cuba se debió más a una iniciativa personal que a un plan estudiado previamente. El P. Lucas Gartéiz, que regresaba a España desde el Perú en 1887, se detuvo unos días en La Habana. Allí pudo comprobar que se mantenía viva en la capital la Tercera Orden Francisca-

8 Juan B. Amores CARredano, «La Iglesia en Cuba al final del periodo colonial», Anuario de Historia de la Iglesia, VII (Pamplona, 1998), pp. 67-83.

9 Ramón SuÁrez PolCARI, Historia de la Iglesia Católica en Cuba, t. II, Miami, Ediciones Universal, pp. 72-168.

10 Antolín ABAD PÉREZ, O.F.M., «Restauración de los colegios en Hispanoamérica», Archivo Ibero-Americano, XLII, 1982, pp. 997-1030. La unidad de las distintas familias franciscanas fue decretada por León XIII en 1897. Diez años antes, en 1878, las provincias españolas volvían a tener reconocimiento civil.

11 Archivo Nacional de Cuba, Gobierno Superior Civil, leg. 387, expediente 14.605, «Número de individuos regulares de que se componen los conventos de la isla según el resumen de la Administración general de rentas terrestres de 12 de septiembre de 1837 ». 
na, que además había sido encargada por las autoridades coloniales para regentar la antigua iglesia y convento de los agustinos tras la desamortización; de hecho, los terciarios eran atendidos por un franciscano, el P. Elías Amézarri, en calidad de capellán. Viendo probablemente aquí una mínima base física y jurídica para plantear a las autoridades el regreso de la orden, nada más llegar a la península el P. Gartéiz solicitó al gobierno, con el acuerdo del comisario general de la orden en España, la autorización para fundar un convento franciscano en Cuba. El ministerio conservador de Cánovas accedió inmediatamente y con fecha 10 de octubre de 1887 se dictaba una real orden al gobernador de la isla para que facilitara un lugar adecuado a los frailes que habrían de llegar. Sólo diez días más tarde salía de Santander la primera expedición de frailes para su nuevo destino antillano.

Estos primeros seis franciscanos llegaron a La Habana en el mes de noviembre de ese mismo año - casi al mismo tiempo que el nuevo obispo Santander y Frutos- y el gobierno insular les asignó inmediatamente la iglesia de Santo Domingo en Guanabacoa, una población aledaña de la capital, precisamente el último lugar donde había quedado un resquicio franciscano tras la desamortización. Poco a poco se reconstruyó el convento, que estaba listo en 1892. Desde aquí se va a expandir la orden de nuevo por toda la isla. El segundo paso se dio en 1896, cuando el obispo Santander entregó definitivamente a la orden el antiguo convento e iglesia de los agustinos, el que venía regentando la Tercera Orden en la misma capital ${ }^{12}$.

La extensión y dureza de la guerra de independencia (1895-98) dieron de nuevo al traste con la recuperación de la labor de la Iglesia, que sufrió tanto en su imagen popular - ya que la jerarquía y mayor parte del clero militaron abiertamente en el bando español- como en su base física y económica, especialmente por la destrucción de iglesias y capillas en los campos.

Fueron necesarios algunos años para que se calmaran las aguas de la revancha y para restaurar el orden social y la maltrecha economía de la isla. Esta fase de restauración económica y de la convivencia social fue, sin embargo, muy rápida; sin duda, ayudaron mucho los estrechos lazos de sangre entre los dos pueblos y la actitud del nuevo gobierno republicano, decidido partidario de favorecer todo lo español - negocios, inmigración, centros regionales- como un medio de compensar la creciente influencia norteamericana ${ }^{13}$. La actitud de la Santa Sede, que supo adaptarse rápidamente a la nueva situación, también favo-

12 Fr. Ezequiel IÑURRIETA, «Los franciscanos en Cuba (1887-1935)», revista San Antonio, La Habana, junio de 1935, pp. 369-383. Ver también Antolín ABAD PÉREZ, «Restauración de los Colegios de Misiones en Hispanoamérica, 1836-1905», Archivo Ibero-Americano, XLII (1982), pp. 997-1030.

13 Hilda Otero y Juan B. Amores, «Las primeras relaciones diplomáticas entre España y Cuba después de 1898», en Josef OPATRNy (ed.), Ibero-Americana Pragensia, Suplementum 9/2001, El Caribe hispano. Sujeto y objeto en política internacional, Praga, 2001, pp. 83-98. 
reció una pronta normalización de las relaciones entre el nuevo gobierno cubano y la Iglesia ${ }^{14}$.

En todo caso, la presencia y actividad de los franciscanos en la isla experimenta un crecimiento espectacular y constante desde la constitución de la República en 1902. A partir de los dos conventos con los que se había iniciado la restauración de la orden, los de Guanabacoa y La Habana, y en sólo dos años, se dobló el número de frailes en la isla, llegando a treinta, y se creó allí una Comisaría dependiente de la provincia española de Cantabria ${ }^{15}$. Los 30 frailes de 1905 se convirtieron en 65 en 1930 y en más de un centenar al advenimiento de la revolución castrista ${ }^{16}$.

Como era habitual en la antigua América española debido a la grave escasez de clero $^{17}$, la jerarquía asignó desde el principio a los franciscanos una tarea pastoral directa, integrando completamente a la orden en la organización eclesiástica de la isla. En concreto, el obispo de La Habana les otorgó en propiedad en 1903 las parroquias de Guanabacoa y la de San Juan de los Remedios, una de las poblaciones más antiguas de la isla, al este de La Habana. A estas dos primeras le seguirían otras once parroquias en toda la isla, además de otras dos grandes iglesias en La Habana, la de San Francisco en el centro de la ciudad y la de San Antonio en el prestigioso barrio residencial de Miramar.

Especial fuerza llegó a adquirir la primera de estas dos, San Francisco, la misma de los agustinos que había sigo asignada a los franciscanos en 1896, como ya vimos, y que fue enteramente reconstruida por los frailes, con gran esfuerzo, hasta que fue reabierta y «rebautizada» con la advocación de su santo fundador en 1925. Este convento e iglesia se convirtió, ya durante los años veinte, en uno de los centros religiosos más activos e influyentes de la capital cubana: allí tenían su sede un buen número de asociaciones piadosas de fieles, además de concentrar una extensa actividad pastoral.

Sin embargo, la presencia de los frailes se hizo mucho más visible y activa entre la población del interior de la isla, a diferencia de otras ordenes y congregaciones cuya actividad se circunscribía a las ciudades grandes o medianas. Así, la gran mayoría de las parroquias que les fueron asignadas a los francisca-

14 Miguel Maza Miquel, «Cuba, Iglesia y Máximo Gómez», Estudios Sociales, 67, San Juan de Puerto Rico, 1987.

${ }^{15}$ Cuba no aparece prácticamente en la legislación general de la orden franciscana para América en los siglos XIX y XX; no llegó a crearse ninguna provincia allí, ni tampoco un vicariato apostólico dependiente de Propagande Fide, como se hizo en América del sur: Cfr. Sebastián García, O.F.M., «América en la legislación general de la Orden Franciscana: 1800-1950», Archivo Ibero-Americano, LVII, 1997, pp. 759-779.

${ }^{16}$ Ismael TESTÉ, Historia eclesiástica de Cuba, t. IV, Barcelona, 1974, p. 40.

17 Eduardo CÁRDENAS, La Iglesia hispanoamericana en el siglo XX (1890-1990), Madrid, Mapfre, 1992, pp. 100-105. 
nos se encontraban en barrios populares del entorno habanero, como el de Casablanca y La Candelaria, o en poblaciones del interior con unos pocos miles de habitantes: Placetas y Unión de Reyes, en la zona intensiva azucarera al este de La Habana; Ciego de Ávila, una población casi nueva, de inmigración, más al centro de la isla; pequeñas poblaciones del oriente, como Guaimaro y Manzanillo, de especiales resonancias por su protagonismo en la guerra de independencia, y la nueva parroquia de Santa Teresita en un barrio popular de Santiago de Cuba, la última en abrirse, hacia $1935^{18}$.

\section{PRINCIPALES CARACTERÍSTICAS DE LA ACTIVIDAD PASTORAL FRANCISCANA EN LA ISLA (1905-1960)}

De acuerdo con la información recopilada por algunos de sus miembros, un total de 110 religiosos franciscanos prestaron sus servicios en Cuba desde la restauración de la orden, en 1887, hasta que se vieron obligados a salir de nuevo de la isla en 1961. Una inmensa mayoría de ellos llevan apellido vasco o navarro, y muchos procedían de la comunidad de Arantzazu en Guipúzcoa, perteneciente a la provincia franciscana de Cantabria ${ }^{19}$.

A la hora de señalar cuáles podrían ser las características específicas de la actividad de los franciscanos en la isla en este periodo, habría que hablar en primer lugar de un esfuerzo prioritario por todo lo que significaba la instrucción religiosa básica, la enseñanza de la doctrina de la fe. La gran orden mendicante acumulaba una experiencia secular en este sentido, pues no en vano constituyó uno de sus principales objetivos fundacionales. Además, esa tarea se adecuaba especialmente a las necesidades de la sociedad cubana, tanto de los sectores mejor situados, entre los que dominaba el indiferentismo consciente, como entre los populares, con un alto índice de indiferentismo práctico; uno y otro fruto en todo caso de la ignorancia, como consecuencia del bajo índice de escolarización y la débil posición de la Iglesia en épocas pasadas, y de la generalización de un ambiente moral profundamente relajado, más que de la falta de disposición para la fe y la práctica religiosa.

En efecto, los testimonios de que disponemos coinciden en sustentar que la primera preocupación de los frailes a los que se encarga una nueva parroquia fue la de poner en marcha cuanto antes todos los instrumentos a su alcance para

18 Una relación bastante completa de los conventos, parroquias y obras de asistencia social atendidos por la comisaría franciscana en Cuba, en Ismael TESTÉ, Historia eclesiástica..., pp. 45-57.

19 Esa información procede de unos apuntes manuscritos que se encuentran en el archivo de dicho monasterio y llevan por título «Labor pastoral de los franciscanos en Cuba. Desde la Restauración (1887) y, sobre todo, su incorporación a la Provincia Franciscana de Cantabria (1904), hasta la Revolución (1959-1961)»; agradezco al P. Joseba Echevarría OFM que me haya facilitado su consulta.

Hispania Sacra, LVIII

118, julio-diciembre 2006, 755-769, ISSN: 0018-215-X 
mejorar la instrucción religiosa del pueblo. En este sentido destacan tres tipos o modalidades de actuación: a) las misiones populares, una actividad que se demostró especialmente idónea para una sociedad de base cristiana pero mal atendida pastoralmente; b) la homilética (sermones y pláticas) de carácter doctrinal, una actividad típica de la orden, que aprovechaba para este fin todas las ocasiones idóneas, como novenas y triduos, además de los tiempos llamados «fuertes» del año litúrgico (Navidad, cuaresma, semana santa); y c) la catequesis y clases de doctrina cristiana en colegios privados de laicos y religiosos.

Así, entre 1905 y 1960, los franciscanos llevaron a cabo más de cien misiones populares, a una media de dos por año, afectando a decenas de miles de personas en cuarenta poblaciones distintas. En esa última fecha eran más de quince mil los niños y niñas que recibían anualmente clases de doctrina cristiana directamente orientadas o dirigidas por los franciscanos (véase apéndice 1). Esos mismos testimonios apuntan a un alto grado de aceptación del estilo de la predicación franciscana por parte de la población, un estilo siempre sencillo, cercano y comprensivo con la condición de la naturaleza humana.

Otra característica señalada de la actividad de la orden franciscana en Cuba fue el fomento de las asociaciones piadosas de fieles, que parecen haberse mostrado como un medio muy adecuado para facilitar la práctica religiosa, la piedad popular y la conexión de los fieles con las iglesias y parroquias. En este sentido conviene señalar que los franciscanos no se limitan, ni mucho menos, a impulsar aquellas devociones o asociaciones que están más ligadas a la tradición de la propia orden, como pudieran ser la misma Orden Tercera o la Pía Unión de San Antonio. Mostrando un alto grado de flexibilidad y adaptabilidad a las preferencias y tradiciones de cada población, en el entorno de las parroquias dirigidas por los frailes encontramos todo tipo de asociaciones: unas tienen una finalidad catequética, como la Cofradía de la Doctrina Cristiana o el Ropero Catecismo de San Antonio; otras, la mayoría, son asociaciones de devoción, desde las que tienen que ver con el culto a la Eucaristía (Adoración nocturna, Archicofradía del Santísimo Sacramento o la de las Marías de los Sagrarios-Calvarios) hasta las marianas (con la Congregación de las Hijas de María en un destacado primer lugar, y otras muchas entre las que se encuentra la de la Virgen de Aránzazu), sin olvidar las de algunos santos más populares (la de San Antonio ya mencionada, san José, san Juan Bosco o santa Teresita). El caso era aprovechar al máximo la tendencia de un pueblo mal que bien educado en unas formas de piedad tradicionales pero efectivas, como medio o instrumento para fomentar la conexión con la iglesia parroquial y garantizar un mínimo de práctica religiosa (véase apéndice 2).

Una de las características aparentemente sorprendente de la actividad de los franciscanos en Cuba, en la primera mitad del siglo XX, fue el destacado papel que les tocó desempeñar en el impulso y dirección espiritual de las nuevas for- 
mas de apostolado seglar de la época, básicamente las que estaban ligadas a la Acción Católica en todas sus modalidades: Federación masculina y femenina de Acción Católica, Juventudes Obreras Católicas, Juventud Estudiantil Católica y Juventud Católica Campesina. Además, los franciscanos jugaron también un papel principal en la puesta en marcha de otra asociación, la de los Caballeros Católicos, que aglutinó desde 1929 a todos lo grupos dispersos y mal organizados antes existentes y que tuvo un singular impacto entre la burguesía cubana $^{20}$.

Fueron los religiosos escolapios y de la Salle los primeros en preocuparse por el asociacionismo seglar católico en Cuba, desde 1920, a partir de las asociaciones de antiguos alumnos de sus colegios y como un medio de dar continuidad a la formación recibida por sus ex alumnos, sobre todo los que habían pasado a la universidad. Así surgió en La Habana la Asociación de Jóvenes Católicos, fundada por el escolapio catalán P. Manuel Serra. La Asociación cobró fuerza en poco tiempo y se hizo notar especialmente con motivo del Primer Congreso Nacional de Estudiantes organizado por la Federación de Estudiantes Universitarios en 1923, donde contribuyó decisivamente a la derrota de una moción del ala más radical de la FEU para erradicar la enseñanza religiosa de la educación secundaria en Cuba. A partir de ahí, el asociacionismo católico creció con fuerza por toda la isla. Los franciscanos fueron elegidos por la jerarquía como directores espirituales de las distintas asociaciones y federaciones de Acción Católica debido a que eran la orden con mayor presencia en toda la isla ${ }^{21}$.

En el hecho de que haya correspondido precisamente a una orden religiosa tradicional, como la de los franciscanos, la dirección e impulso de esta nueva forma de apostolado seglar, que recibía en estas décadas una atención especial de la jerarquía católica en todo el mundo, se puede advertir una prueba evidente, junto a la capacidad de adaptación de la orden franciscana, de la debilidad de la estructura eclesial diocesana en la isla, perfectamente explicable por razones históricas y sociológicas que quedan apuntadas ${ }^{22}$. Algo parecido ocurría en el resto de América latina ${ }^{23}$.

Aunque no era uno de sus objetivos principales, los franciscanos también pusieron en marcha colegios de primera y segunda enseñanza para niños y niñas: hacia 1960 dirigían catorce, en los que se educaban más de 1.600 alumnos de uno y otro sexo, la gran mayoría de ellos en régimen de enseñanza gratuita o semigratuita. Impulsaron y gestionaron además diversas obras de carácter asis-

\footnotetext{
20 Revista San Antonio, La Habana, junio de 1935, pp. 342-344.

21 Teresa FernÁndez SoneIRA, Con la estrella y la cruz. Historia de la Federación de la Juventudes de Acción Católica cubana, vol. 1, Miami, Ediciones Universal, 2002, cap. I.

22 Cf. Miguel Maza MiQuel, El alma del negocio y el negocio del alma. Testimonios sobre la Iglesia y la sociedad en Cuba, 1878-1894, Santiago de los Caballeros (Santo Domingo), 1990.

23 E. CÁRdENAS, La Iglesia hispanoamericana..., pp. 199-200.
} 
tencial, principalmente dispensarios médicos y asilos para niños, cubriendo así una necesidad especialmente urgente entre las abandonadas clases bajas de la sociedad cubana. En esta misma línea, otra actividad concreta que resultaba muy útil para el mercado de trabajo en el mundo urbano de Cuba, en el que siempre destacó el sector servicios, eran las academias de corte y costura: la modistería y sastrería siempre fueron dos actividades bien remuneradas en la isla. La gestión diaria y atención de estos centros la llevaban a menudo los hombres y mujeres de las diversas asociaciones ligadas a la Acción Católica, que colaboraban estrechamente además en otras obras de carácter mixto, asistencial y catequético.

Por último, pero no por eso menos importante, hay que señalar la intensa actividad de los franciscanos ligada al apostolado de los medios de comunicación, destacando las revistas y boletines como El Faro, en Mariel, El Caballero católico, en Camanuaní y, sobre todo, la revista quincenal San Antonio, más tarde denominada Semanario Católico y finalmente La Quincena, que llegó a editar más de diez mil ejemplares en los años treinta debido a su interés no sólo desde el punto de vista religioso o doctrinal sino también cultural y literario ${ }^{24}$.

\section{UNA PUJANTE LABOR FRUSTRADA FINALMENTE POR LA REVOLUCIÓN}

Como en casi todos los aspectos del desarrollo de la sociedad cubana, resulta imposible aventurar cuál habría sido el efecto de la actividad de la orden franciscana en Cuba de no haber tenido lugar el largo proceso revolucionario castrista, que cortó casi de raíz, a partir de 1961, la creciente pujanza de la Iglesia católica en Cuba, de la que la misma revolución se benefició en sus orígenes, como es conocido.

Una prueba clara de esa pujanza la tenemos en la ingente labor llevada a cabo por los franciscanos estos años, como indican de alguna manera los datos básicos recogidos en las relaciones anejas. Lógicamente, la eficacia real de toda esa labor resulta imposible de medir en cifras, pero se antoja impresionante, sobre todo si tenemos en cuenta la debilidad de la Iglesia en la etapa anterior de la historia cubana. Resulta más visible la eficacia de esa labor en lo que se refiere al incremento de la práctica religiosa, muy especialmente en algunas poblaciones relativamente pequeñas, como Guanabacoa, Placetas y Manzanillo, donde la asistencia a la misa dominical (el dato siempre más significativo) alcanzaba el ocho o diez por ciento de la población, cuando la media nacional no superaba el uno por cien. Algunos datos de las décadas de 1920 y 1930 demuestran que se había conseguido mucho en poco tiempo: el incremento de las comuniones,

24 Antolín ABAD PÉREZ, «Restauración...», p. 1024. 
como dato más significativo, fue de un 30\% entre 1924 y 1932 en la iglesia de San Francisco de La Habana; y en Guanabacoa, aumentó en un 50\% entre 1927 y 1932.

A esto hay que sumar toda la actividad desplegada entre las gentes del campo, a través de capillas que se revitalizaron o construyeron de nueva planta en aldeas y centrales azucareras: hacia 1960 eran 64 las capillas rurales atendidas por ellos en toda la isla. La mayoría de estas gentes del campo era la primera vez que tenía acceso a cualquier tipo de instrucción y, por supuesto, a la atención religiosa; un efecto inmediato fue la regularización de un gran número de uniones ilegítimas desde el punto de vista canónico y el bautismo de miles de niños.

Otras iniciativas, como la de los Caballeros Católicos, tendrían un efecto social no contabilizable pero sin duda relevante, pues suponía un intento de cambiar una mentalidad muy extendida en aquella sociedad que ligaba práctica religiosa a sexo femenino, especialmente entre las clases medias y altas.

Toda esta actividad puede ocultar la dura realidad diaria, que llevaba a la mayor parte de los religiosos - prácticamente todos salvo los que residían en los conventos de La Habana y Guanabacoa - a vivir en un ambiente de gran austeridad y pobreza, dado que la gran mayoría de las parroquias se localizaban en zonas de escasos recursos.

De los resúmenes de los informes de las visitas canónicas de los superiores de la provincia se deduce que les preocupaba la dificultad de sostener la vida conventual y el espíritu de la orden en medio de una actividad tan absorbente y de un ambiente moral que dejaba mucho que desear. Sin embargo, llama la atención que, de los 110 religiosos que residieron en Cuba desde 1890 hasta 1960, sólo once de ellos colgaron los hábitos, y hay además que suponer que los motivos podrían ser muy diversos. Por otro lado, parece que cualquier intento de los superiores de la orden por suprimir alguna misión o dejar alguna parroquia chocaba inevitablemente con el interés de la jerarquía diocesana local, siempre quejosa de la falta de pastores en la isla. En realidad, el propio visitador decía, en 1916, que el personal de la orden era claramente insuficiente para atender todo el peso que se le había asignado ${ }^{25}$.

El advenimiento de la revolución en 1959, y sobre todo la clara orientación social comunista que adquiere oficialmente desde 1961, acabó con toda esta labor casi de golpe. A partir del mes de abril de ese último año, la hostilidad creciente de la nueva dirección política del país hacia toda la actividad de la Iglesia, se convirtió en una sucesión ya continua de controles, dificultades, vejaciones, intensas campañas denigrativas, etc., hasta que se decidió la expul-

25 «Labor pastoral de los franciscanos en Cuba», pp. 74-85.

Hispania Sacra, LVIII

118, julio-diciembre 2006, 755-769, ISSN: 0018-215-X 
sión de la mayor parte del clero con la excusa de que era un sector compuesto en su mayoría por extranjeros y, por lo mismo, potencialmente contra revolucionario. No obstante, quedaron algunos representantes de diferentes órdenes religiosas, entre ellas los franciscanos, concretamente en el convento del barrio de Miramar de La Habana, en el de Guanabacoa y en San Juan de los Remedios. A día de hoy apenas superan la docena de frailes, algunos de ellos ancianos y enfermos. Las escasas vocaciones que tienen suelen salir a formarse al extranjero y es raro que regresen; y las autoridades sólo permiten entrar a un franciscano extranjero para sustituir, por fallecimiento o salida del país, de alguno de los que ya residen allí.

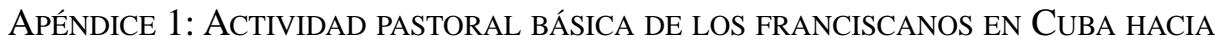
$1960^{26}$

\begin{tabular}{|c|c|c|c|c|c|c|c|c|}
\hline Iglesia o parroquia & Frailes & m.d. & Asist. & Baut.(1) & Matr.(1) & Com.(1) & Capillas & Catq. \\
\hline Guanabacoa convento ...... & 13 & 4 & 400 & & & 25.000 & 2 & 60 \\
\hline Guanabacoa* ......................... & & 11 & 1.000 & 1.300 & 140 & 30.000 & 4 & 925 \\
\hline La Habana convento ........ & 20 & 16 & 2.000 & 210 & 185 & 100.000 & 4 & 1.800 \\
\hline Casa Blanca* ......................... & & 3 & 180 & 78 & 16 & $?$ & & 120 \\
\hline San Antonio Miramar ...... & 11 & 8 & & & & 65.000 & & \\
\hline Remedios* ${ }^{*} \ldots \ldots \ldots \ldots \ldots \ldots \ldots$ & 3 & 8 & 730 & 830 & 30 & 12.000 & 7 & 1.000 \\
\hline Candelaria* ..... & 3 & 5 & 400 & 300 & 8 & 4.500 & 4 & 165 \\
\hline Mariel* $^{*}$....... & 4 & 6 & 500 & 300 & 20 & 3.600 & 3 & 350 \\
\hline Placetas* ............. & 4 & 11 & 1.300 & 1.200 & 50 & 18.000 & 9 & 175 \\
\hline San Cristóbal* ${ }^{*} . . . \ldots \ldots \ldots \ldots$ & 3 & 5 & 350 & 640 & 20 & 7.500 & 3 & 600 \\
\hline Clarisas capellanía........... & 3 & 2 & 400 & 25 & & 4.400 & & \\
\hline Camajuaganí* ......... & 2 & 4 & 450 & 550 & 10 & 8.000 & 1 & 300 \\
\hline Santa Cruz Jerusalén. & 7 & 8 & 1.900 & 420 & & 35.000 & 1 & 600 \\
\hline Unión de Reyes* .. & 3 & 5 & 540 & 380 & 12 & 4.200 & 3 & 600 \\
\hline Guaimaro* ........... & 4 & 8 & 1.100 & 970 & 25 & 14.000 & 5 & 1.200 \\
\hline Manzanillo* & 7 & 11 & 2.600 & 2.500 & 120 & 60.000 & 6 & 2.500 \\
\hline Ciego de Avila* & 7 & 13 & 3.000 & 2.100 & 75 & 42.500 & 12 & 1.300 \\
\hline $\mathrm{S}^{\mathrm{a}}{ }^{\mathrm{a}}$ Teresita $\left(\right.$ Santiago) ${ }^{*} \ldots$ & 3 & 3 & 800 & 500 & 50 & 8.000 & & 700 \\
\hline Total (18 iglesias) .............. & 103 & 131 & 17.650 & 12.503 & 761 & 442.000 & 64 & 12.295 \\
\hline
\end{tabular}

Leyenda:

* Parroquia; m.d.: misas dominicales; Asist.: total de asistentes a las misas dominicales.

(1) Promedio anual, en los tres casos (bautismos, matrimonios y comuniones); Capillas: capillas rurales dependientes de las parroquias; Catq.: total de niños en catequesis.

26 Los datos de estos Apéndices están sacados de «Apuntes...». 
APÉNDICE 2: OBRAS ASISTENCIALES Y DE ENSEÑANZA

Centros de asistencia social:

Ciudad de los Niños «Mi Casa», en La Habana, 65 niños

Dispensario S. Francisco de Asís, Guanabacoa

Asilo de niños del Cotorro

Asilo de Triscornia

Dispensarios médicos: 2

Colegios que dirigen: 14, con un total de más de 1.600 alumnos de ambos sexos, la mayoría de elemental y primaria, a saber:

Guanabacoa: $\quad$ Escuela Ntra Sra de Guadalupe: 134 niños, gratuita Colegio San Francisco: 100 niños, gratuita

La Habana: Instituto Superior de Filosofía y Sociología cristianas

Colegio San Antonio: 300 niños, gratuito

Colegio para niños chinos: 100 niños, semigratuito

Escuela parroquial en La Candelaria: 80 niños; semigratuito

Placetas:

Colegio San Antonio, 100 niños, de pago

Manzanillo: $\quad$ Colegio San Juan Bosco: 60 alumnos

Escuela San Tarsicio: 130 alumnos

Colegio Santa Teresa: 250 alumnas de secundaria

Colegio Santo Tomás: 65 alumnos, de pago

Santiago de Cuba: Escuela parroquial Santa Teresita: 100 niños y niñas

Escuela del hogar: 50 alumnas

Atienden además 8 colegios de religiosas y 2 de religiosos (Hermanos de La Salle)

Otras:

Residencia universitaria femenina, La Habana, 30 residentes

Roperos y academias gratuitas de corte y confección

Reparto de limosnas, víveres y ropas

Atención de enfermos

Atención de presos

Revistas y emisiones radiofónicas 
ApÉNDICE 3: AsOCIACIONES DE FIELES DIRIGIDAS POR LOS FRANCISCANOS

\begin{tabular}{|c|c|c|}
\hline Tipo de asociación & Sedes o grupos & Socios \\
\hline Terceras Órdenes & \multirow{5}{*}{10} & \\
\hline Hermandad de Tercera Orden Franciscana . & & 1.500 \\
\hline Hermandad Tercera Orden Servita ................ & & 64 \\
\hline Asociaciones de Acción Católica & & \\
\hline Federaciones* & & 2.200 \\
\hline Caballeros Católicos & 12 & 735 \\
\hline Caballeros de Colón . & 5 & 320 \\
\hline Maestras católicas . & \multirow[t]{2}{*}{2} & 78 \\
\hline 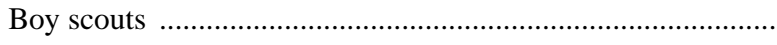 & & 70 \\
\hline \multicolumn{3}{|l|}{ Catequéticas } \\
\hline 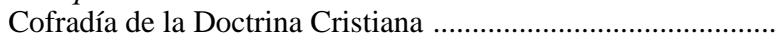 & 4 & 255 \\
\hline 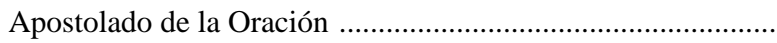 & 6 & 480 \\
\hline 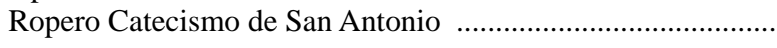 & 11 & 150 \\
\hline Asociaciones de devoción & \multirow{4}{*}{2} & \\
\hline 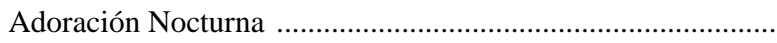 & & 35 \\
\hline 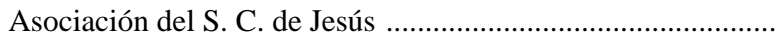 & & 300 \\
\hline Asociación del Vía Crucis & & 215 \\
\hline 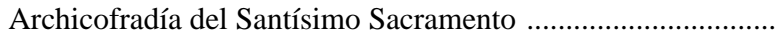 & \multirow[t]{4}{*}{3} & 300 \\
\hline Archicofradía de Marías de los Sagrarios-Calvarios ................... & & 214 \\
\hline 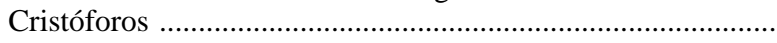 & & 28 \\
\hline 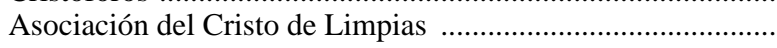 & & 45 \\
\hline 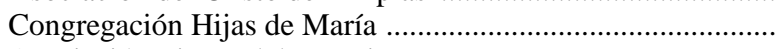 & \multirow[t]{4}{*}{5} & 680 \\
\hline 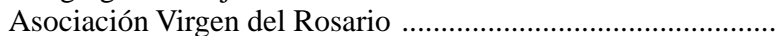 & & 115 \\
\hline 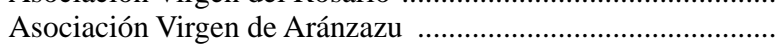 & & 45 \\
\hline 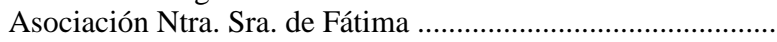 & & 38 \\
\hline Cofradía de la Caridad & 7 & 665 \\
\hline 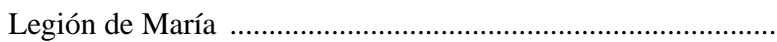 & 2 & 46 \\
\hline Asociación del Carmen & \multirow[t]{2}{*}{3} & 160 \\
\hline Asociación de San José & & 180 \\
\hline 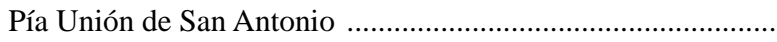 & \multirow[t]{2}{*}{5} & 500 \\
\hline 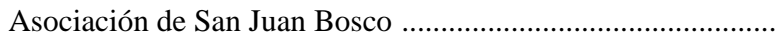 & & 47 \\
\hline 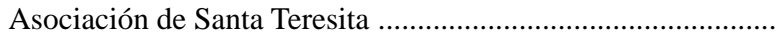 & \multirow[t]{3}{*}{2} & 200 \\
\hline 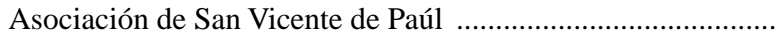 & & 15 \\
\hline 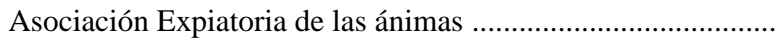 & & 123 \\
\hline
\end{tabular}

